\title{
Delimitação e monitoramento vegetativo da bacia hidrográfica do Lajeado Chiquinha
}

\author{
Vanessa Deisi Renz', Luciana Gregory Ritter², Sabrina Rodrigues da Conceição³, \\ Giovana Garlet ${ }^{4}$, Aline Hass ${ }^{5}$ \\ 1, 3, 4, 5 Universidade Federal de Santa Maria, Santa Maria, RS, Brasil \\ ${ }^{2}$ Universidade Federal de Santa Maria, Frederico Westphalen, RS, Brasil
}

\section{Resumo}

A agricultura, pecuária e indústria são atividades econômicas, que necessitam de grandes áreas, onde o desmatamento é a primeira consequência negativa para o ambiente, onde o estudo e o manejo integrado das bacias hidrográficas são os únicos caminhos a serem seguidos para o diagnóstico bem como a recuperação ambiental dessas unidades, conduzindo ao equilíbrio dos ecossistemas ali existentes. Sendo assim, o objetivo do presente trabalho é a delimitação da Bacia Hidrográfica do Lajeado Chiquinha através do software Quantum GIS (QGIS), aliado a utilização de imagens do software Google Earth para o monitoramento da vegetação através de análise temporal. Utilizou-se a ferramenta chamada imagens históricas do Google Earth para fazer a análise temporal da presença de vegetação no entorno do lajeado, acompanhando assim as mudanças ocorridas durante períodos específicos de tempo. A ausência de vegetação ao longo de toda a extensão do percurso do lajeado, além de estar em desacordo com as exigências previstas em lei, diminui a preservação do local e a manutenção da biodiversidade, afetando também as taxas de infiltração no solo e o escoamento superficial.

Palavras-chave: preservação; monitoramento; bacia hidrográfica;

\begin{abstract}
The agriculture, livestock and industry are economic activities that require large areas where deforestation is the first negative consequence for the environment where the study and the integrated management of river basins are the only ways to be followed for the diagnosis and as the environmental recovery of these units, leading to balanced ecosystems therein. Thus, the aim of this work is the delineation of the Basin Paved Chiquinha through software Quantum GIS (QGIS), combined the use of Google Earth software images for vegetation monitoring through temporal analysis. We used a tool called historical images from Google Earth to the temporal analysis of the presence of vegetation surrounding the paved, thus following the changes during specific periods of time. The lack of vegetation along the entire length of the paved, besides being in violation of the requirements set forth in law, decreases site preservation and maintenance of biodiversity, also affecting the rates of soil infiltration and runoff.
\end{abstract}

Keywords: preservanção; monitoring; watershed; 


\section{INTRODUÇÃO}

De acordo com a Lei $n^{\circ}$ 6.938, da Política Nacional de Meio Ambiente - PNMA, a bacia hidrográfica é considerada a unidade geográfica ideal para o planejamento e zoneamentos ambientais, usando como unidade de planejamento, pois as bacias possuem características ecológicas, geomorfológicas e sociais integradoras, o que possibilita uma abordagem holística e participativa envolvendo estudos interdisciplinares para o estabelecimento de formas de desenvolvimento sustentável inerentes ao local ou região onde foram implementados (Attanasio, 2004).

Donadio et al. (2005), enuncia que nas bacias com cobertura de floresta natural, a vegetação promove a proteção contra a erosão do solo, a sedimentação e a lixiviação excessiva de nutrientes, sendo essas áreas muito importantes para manter o abastecimento de água de boa qualidade. Por outro lado, as práticas que se seguem após a retirada das árvores tendem a produzir intensa e prolongada degradação da qualidade da água.

De acordo com Carvalho (2000), tanto a agricultura como a pecuária são atividades econômicas, que necessitam de grandes áreas, onde o desmatamento é a primeira consequência negativa para o ambiente, deixando o solo exposto à lixiviação, favorecendo o carregamento de sedimentos para os rios e lagos, podendo acarretar no aumento do uso de fertilizantes, desequilibrando o conteúdo de nutrientes do solo e facilitando a contaminação química do ambiente.

Os fenômenos acorridos dentro de uma bacia, sejam eles de origem natural ou antrópica, interferem na dinâmica sistêmica, na quantidade e qualidade dos cursos de água e as medidas de algumas de suas variáveis (solo, clima, vegetação, relevo, entre outros) permitem compreender a soma desses fenômenos (Corseuil, 2006).

E, segundo Rocha (1997), o estudo e o manejo integrado das bacias hidrográficas são os únicos caminhos a serem seguidos para o diagnóstico bem como a recuperação ambiental dessas unidades, conduzindo ao equilíbrio dos ecossistemas ali existentes.

Sendo assim, o objetivo do presente trabalho é a delimitação da Bacia Hidrográfica do Lajeado Chiquinha através do software Quantum GIS (QGIS), aliado a utilização de imagens do software Google Earth para o monitoramento da vegetação através de análise temporal.

\section{I.I LOCALIZAÇÃo E CARACTERIZAÇÃo DA ÁREA DE ESTUdo}

O município de Frederico Westphalen está localizado na região Norte do Estado de Rio Grande do Sul, conforme figura 1 . A uma latitude $27^{\circ} 21^{\prime} 33^{\prime \prime}$ sul e a uma longitude $53^{\circ} 23^{\prime} 40^{\prime \prime}$ oeste, estando
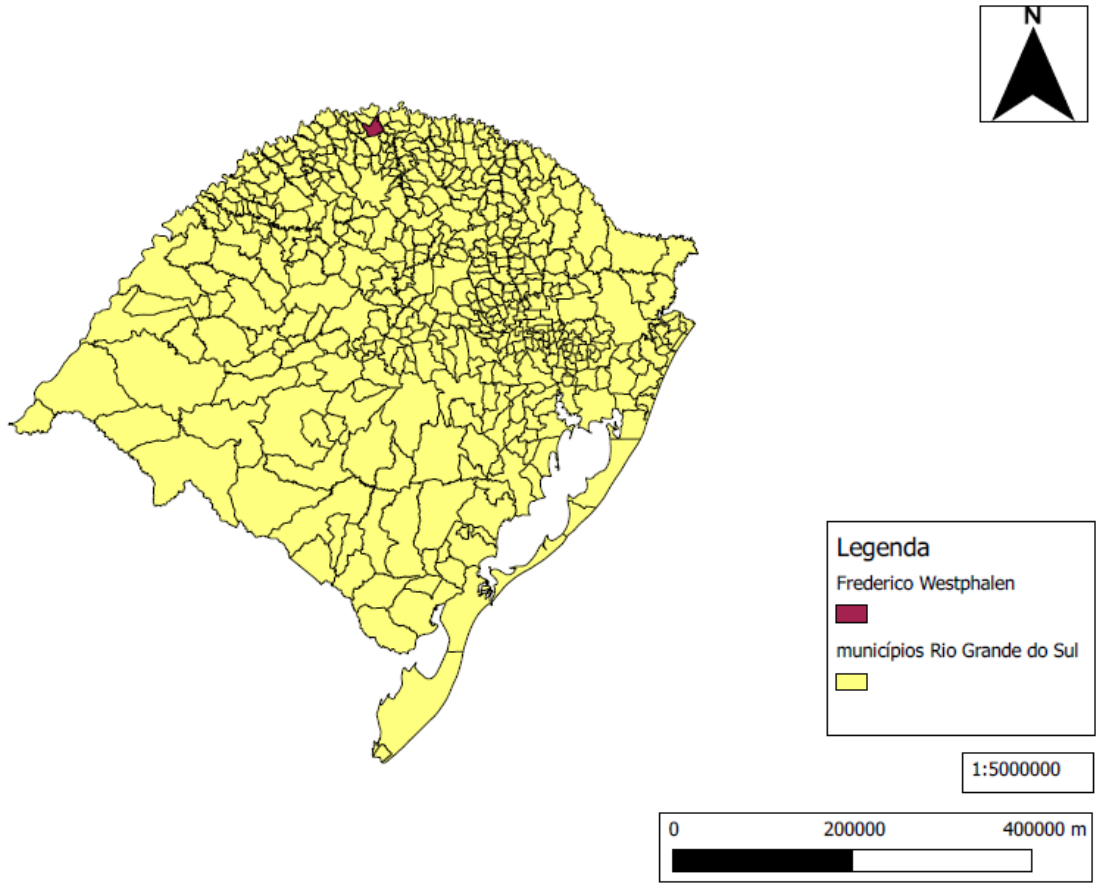

Figura 1. Localização do município de Frederico Westphalen

Fonte: Autoria própria 
a uma altitude de 566 metros. Possui uma população de 28.848 habitantes (IBGE, 2010) e uma área de $264,53 \mathrm{~km}^{2}$.

O clima da cidade de Frederico Westphalen é do tipo Cfb segundo a classificação de Köppen com temperatura média anual em torno de $18^{\circ} \mathrm{C}$, podendo atingir máximas de $41^{\circ} \mathrm{C}$ no verão e mínimas inferiores a $0^{\circ} \mathrm{C}$ no inverno. A precipitação média anual varia entre 1.800 e $2.100 \mathrm{~mm}$, bem distribuídos durante o ano (Bernardi et al., 2008).

A Bacia Hidrográfica Rio da Várzea situa-se ao norte do Estado do Rio Grande do Sul, entre as coordenadas geográficas $27^{\circ} 00^{\prime}$ a $28^{\circ} 20^{\prime}$ de latitude Sul e $52^{\circ} 30^{\prime}$ a $53^{\circ} 50^{\prime}$ de longitude Oeste. Abrange a Província Geomorfológica Planalto Meridional. Possui uma área de $9.463,46 \mathrm{Km}^{2}$, abrangendo 55 municípios. As atividades econômicas são predominantemente agrícolas, com lavouras de soja, trigo e milho, bem como avicultura e suinocultura. Destaca-se, ainda, o potencial hidrelétrico desta bacia e as atividades de mineração (extração de pedras preciosas e semipreciosas, como ágata, ametista, etc.) (Prefeitura Municipal de Frederico Westphalen/RS, 2011).

A Micro Bacia Lajeado Chiquinha tem sua nascente principal localizada na zona urbana de Frederico Westphalen e a foz no Rio da Várzea, com uma área de 8361 ha, conforme figura 2.

A principal atividade econômica da região é desenvolvida no meio rural através da agricultura, pois segundo Borghetti et. tal., (2008) é uma região caracteriza-se por terras férteis e solos com altos índices de produtividade. As atividades agrícolas envolvem no processo produtivo substâncias químicas como agrotóxicos (herbicidas, inseticidas, fungicidas), fertilizantes e a geração de resíduos e poluentes, que em última análise, provocam a contaminação do solo e água.

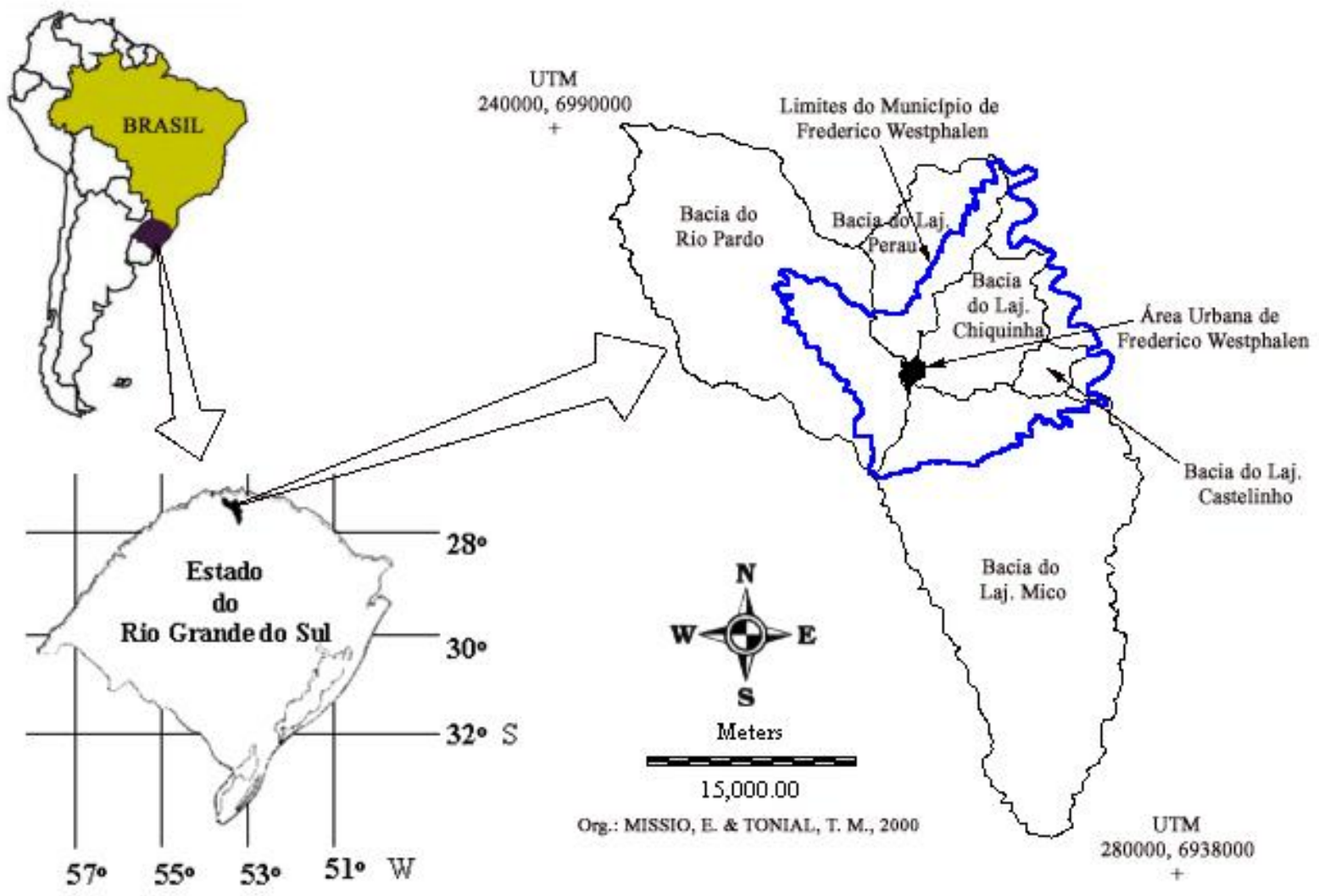

Figura 2. Localização da Micro Bacia do Lajeado Chiquinha

Fonte: http://www.seb-ecologia.org.br/forum/art14.htm 


\section{METODOLOGIA}

Inicialmente foi realizada a delimitação do rio Lajeado Chiquinha e sua respectiva micro bacia, através do software Quantum GIS (QGIS), conforme figura 3, em uma carta na escala 1:50.000, com Datum Horizontal no Sistema Córrego Alegre, fornecida pelo Exército Brasileiro.

A etapa seguinte consistiu na migração para o Google Earth dos dados referentes à micro bacia, possibilitando assim a análise visual referente à vegetação do entorno do lajeado, para tal os dados foram convertidos do formato shapefile para Keyhole Markup Language (KML), formato compatível com o Google Earth.

Utilizou-se a ferramenta chamada imagens históricas do Google Earth para fazer a análise temporal da presença de vegetação no entorno do lajeado, acompanhando assim as mudanças ocorridas durante períodos específicos de tempo.
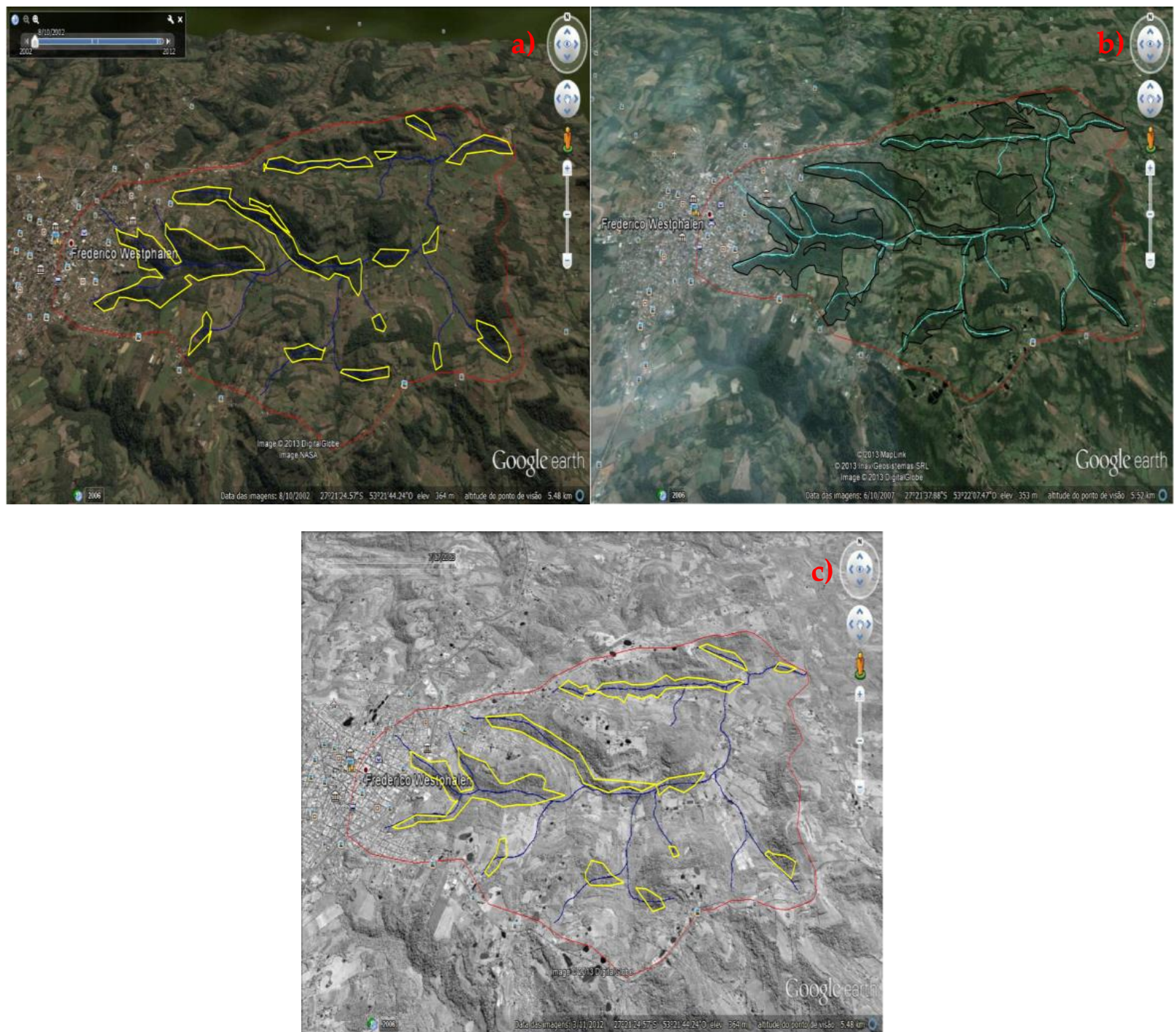

Figura 3. Delimitação da Micro Bacia do Lajeado Chiquinha, Frederico Westphalen, RS.

Fonte: Autoria própria. 


\section{RESULTADOS E DISCUSSÃO}

Através da análise temporal, verificou-se que a quantidade de vegetação apresenta uma diminuição significativa ao longo do tempo, conforme figura 3, o que representa impactos a disponibilidade e quantidade de água da bacia.

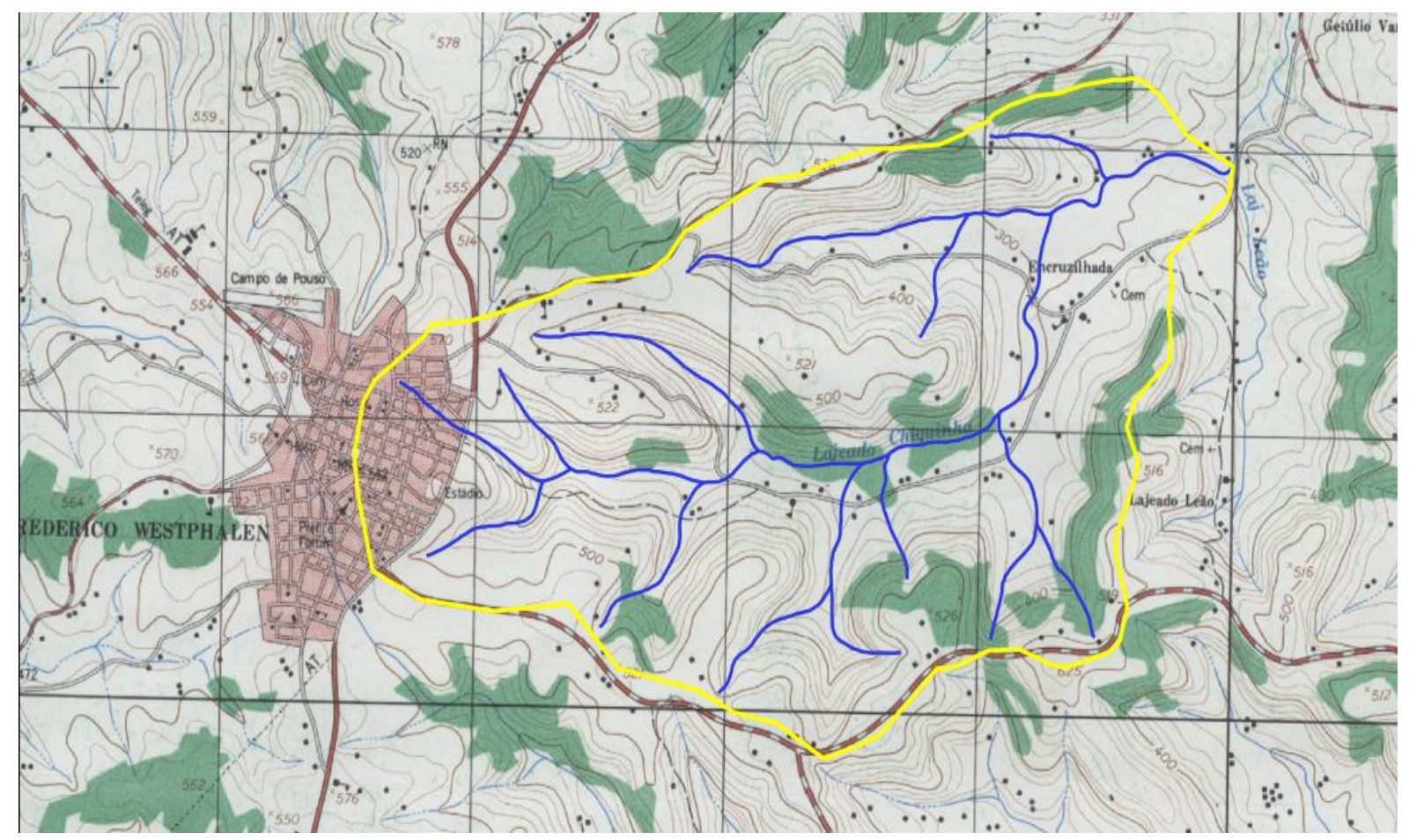

Figura 3. Vegetação no entorno do Lajeado Chiquinha nos anos de 2002 (a), 2006 (b) e 2013 (c).

Também observou-se a ausência de vegetação ao longo de todo o percurso do rio, a qual está associada ao desenvolvimento da atividade agrícola e industrial dentro da bacia.

Algumas das principais empresas do município estão localizadas na área urbana ou no seu entorno. A localização da área urbana, na parte mais alta do município, coincide com a localização das nascentes, sendo que este aspecto, aliado ao recente e ainda deficiente sistema de tratamento de efluentes urbanos, que até o momento cobre apenas alguns bairros, é um dos principais fatores de degradação e contaminação ambiental que atinge, além da área urbana, extensões bem maiores, a partir da contaminação das nascentes, sendo este fator de degradação encontrado na área de abrangência do Rio Chiquinha (OTTONELLI, 2005).

\section{CONCLUSÃO}

O modelo de civilização geradora da crise ambiental pela qual passamos é o resultado da relação desmistificada e utilitarista do homem com a natureza, onde o ser humano está promovendo a degradação do ambiente, o que afeta a sua própria saúde.

A ausência de vegetação ao longo de toda a extensão do percurso do lajeado, além de estar em desacordo com as exigências previstas em lei, diminui a preservação do local e a manutenção da biodiversidade, afetando também as taxas de infiltração no solo e o escoamento superficial.

A promoção do manejo integrado de bacias hidrográficas, com o auxílio do monitoramento através de softwares, contribui para a gestão sustentável do ambiente, garantindo assim a sua integridade e os usos futuros. 


\section{REFERÊNCIAS}

ATTANASIO, C. M. Planos de manejo integrado em microbacias hidrográficas com uso agrícola: uma abordagem hidrológica na busca da sustentabilidade. 2004. 193 p. Tese (Doutorado em Recursos Florestais) Escola Superior de Agricultura "Luiz de Queiroz" Universidade de São Paulo, Piracicaba. 2004.

BERNARDI, I. P.; TEIXEIRA, E. M.; JACOMASSA, F. A. F. Registros relevantes da avifauna do ALTO URUGUAI, RIO GRANDE DO SUL, BRASIL. BIOCIÊNCIAS, Porto Alegre, v. 16, n. 2, p. 134-137, jul. 2008.

BORGHETTI, Nadia Rita Boscardin, BORGHETTI, José Roberto, ROSA FILHO, Ernani Francisco da AQÜÍFERO GUARANÍ Edição on-line 214 Páginas. Disponível em: < http://www.oaquiferoguarani.com.br/ index $02 . h t m>$.

CARVALHO, N. de O. Hidrossedimentologia Prática. Rio de Janeiro: Companhia de Pesquisa em Recursos Minerais, 2000. 372p.

CORSEUIL, C. W. Técnicas de geoprocessamento e de análise de multicritérios na adequação de uso das terras. 2006. 101 f. Tese (Doutorado em Agronomia/Energia na Agricultura)-Faculdade de Ciências Agronômicas, Universidade Estadual Paulista, Botucatu, 2006.

DONADIO, N. M. M., et al. Qualidade da água de nascentes com diferentes usos do solo na bacia hidrográfica do córrego rico, São Paulo, Brasil. Engenharia Agrícola. Jaboticabal, v. 25, n. 1, p. 115-125, jan-abr. 2005.

OTTONELLI, M. Diagnóstico da qualidade da água do rio Chiquinha, município de Frederico Westphalen, RS, a partir do estudo de Diatomáceas. 2005. 52f. Monografia (Licenciatura em Ciências Biológicas) - Universidade Regional Integrada do Alto Uruguai e das Missões, Campus de Frederico Westphalen, 2005.

PREFEITURA MUNICIPAL DE FREDERICO WESTPHALEN. Grupo de Trabalho PMSB-FW. Plano Municipal de Saneamento Básico de Frederico Westphalen/RS. Frederico Westphalen, 2011.

ROCHA FILHO, J.; PRIMAVESI, O. Aplicação do SIG-IDRISI para Estudo e Classificação das Áreas de Proteção dos Recursos Naturais na Fazenda Canchim (EMBRAPA São Carlos - SP). In: II Simpósio de Usuários IDRISI, II., 1997, Campinas. Caderno de Resumos... Campinas: UNICAMP/FEAGRI. FPE/Faculdade de Agronomia "Manoel Carlos Gonçalves" e EMBRAPA/CNPTIA, 1997. p. 5-7. 